\title{
Spontaneous absolute asymmetric synthesis promoted by achiral amines in conjunction with asymmetric autocatalysis
}

\author{
Kenta Suzuki, Kunihiko Hatase, Daisuke Nishiyama, Tsuneomi Kawasaki, Kenso Soai
}

\begin{abstract}
The origin of homochirality of organic compounds such as L-amino acids and D-sugars have intrigued many scientists, and several hypotheses regarding its homochirality have been proposed. According to the statistical theory, small fluctuations in the ratio of the two enantiomers are present in a racemic mixture obtained from the reaction of achiral molecules.

We report herein the reaction of pyrimidine-5-carbaldehyde and diisopropylzinc in the presence of achiral amine such as $N, N^{\prime}$-dimethylpiperazine, $N, N^{\prime}$-diethylpiperazine or $N$-methylmorpholine but in the absence of a chiral substance. The stochastic formation of (S)- and (R)-pyrimidyl alkanols with detectable ee was observed. This study shows that the slight fluctuation of the enantiomeric ratio of pyrimidyl alkanol produced at the initial reaction step can be enhanced significantly in conjunction with asymmetric autocatalysis with amplification of enantiomeric excess. We believe that the stochastic behavior in the formation of pyrimidyl alkanol constitutes one of the conditions necessary for spontaneous absolute asymmetric synthesis.
\end{abstract}

\section{Background}

The origin of biomolecular homochirality such as Lamino acids and D-sugars is an interesting mystery [1-6]. Spontaneous absolute asymmetric synthesis [1], that is, the synthesis of enantioenriched products from achiral conditions in the absence of a chiral substance, has been proposed as one of the origins of chirality. Spontaneous asymmetric crystallization of achiral compounds is another of the proposed mechanisms of homochirality [7-10]. However, spontaneous absolute asymmetric synthesis without using chiral compounds differs from crystallization in that it is possible for an increase in the amount of chiral compound to occur. Experimental realization of spontaneous absolute asymmetric synthesis via asymmetric autocatalysis has been a challenge, although the theories have been proposed [11-13].

During our continuing studies of asymmetric autocatalysis [14-25], we have observed asymmetric autocatalysis of 5-pyrimidyl alkanols in the enantioselective addition of diisopropylzinc $\left(i-\mathrm{Pr}_{2} \mathrm{Zn}\right)$ to pyrimidine-5-carbaldehyde.

\footnotetext{
* Correspondence: soai@rs.kagu.tus.ac.jp

Department of Applied Chemistry and Research Institute for Science and Technology, Tokyo University of Science, Kagurazaka, Shinjuku-ku, Tokyo 1628601, Japan
}

It is noteworthy that, even when an asymmetric autocatalyst with an extremely low ee was used as the initial catalyst, an almost enantiomerically pure product, i.e., asymmetric autocatalysis, could be obtained by consecutive reactions [16]. For example, when pyrimidyl alkanol with ca. $0.00005 \%$ ee was used as the initial catalyst, almost enantiomerically pure ( $>99.5 \%$ ee) product was obtained after three consecutive asymmetric autocatalytic reactions [16]. Moreover, a variety of chiral organic compounds $[26,27]$ and inorganic crystals including isotopically chiral compounds [28,29], inorganic crystals such as quartz [30], organic crystals of achiral compounds $[31,32]$ and even a physical chiral factor, that is, right- or left-handed circularly polarized light [33], can act as chiral initiators to afford 5-pyrimidyl alkanol with a high ee in conjunction with asymmetric autocatalysis, with the product having an absolute configuration corresponding to that of the chiral initiators.

On the other hand, from the standpoint of statistics, small fluctuations in the ratio of the two enantiomers are expected to be present in racemic mixtures of chiral molecules $[1,34,35]$. We envisaged that when the reaction system involves asymmetric autocatalysis with amplification of ee, the initial small imbalance of 
enantiomers in racemic mixtures that arises from the reaction of achiral reactants becomes overwhelming to afford a highly enantiomerically enriched product [36-44].

We have reported that without adding any chiral substance, enantioenriched $(S)$ - or $(R)$-pyrimidyl alkanol 2 is generated in an approximately stochastic distribution from the reaction between pyrimidine-5-carbaldehyde 1 and $i-\operatorname{Pr}_{2} \mathrm{Zn}$ in conjunction with asymmetric autocatalysis [45-48].

\section{Results and Discussion}

We previously reported that dialkylzincs are activated by amines to add to aldehydes [49,50]. Because an amine is a Lewis base, it coordinates to the zinc atom of dialkylzinc
[51], and this coordination enhances the nucleophilic character of the dialkylzinc. We reasoned as follows: when achiral amine is added to the reaction between aldehyde $\mathbf{1}$ and $i-\mathrm{Pr}_{2} \mathrm{Zn}$, the achiral amine acts as a catalyst to promote the formation of racemic alkanol 2 with statistical fluctuation of chirality. The initial enantioenrichment would be amplified by the subsequent asymmetric autocatalysis to afford $(S)$ - or $(R)$-alkanol 2.

Here, we report that the enantioenriched pyrimidyl alkanol 2 is generated from the reaction between pyrimidine-5-carbaldehyde 1 and $i$ - $\operatorname{Pr}_{2} \mathrm{Zn}$ in conjunction with asymmetric autocatalysis under achiral conditions in the presence of an achiral amine, such as $N, N^{\prime}$ dimethylpiperazine $3, N, N^{\prime}$-diethylpiperazine 4 or $N$ methylmorpholine 5 (Figure 1).<smiles>[R17][PH2+][OH+]</smiles>

Toluene, $0^{\circ} \mathrm{C}$

Achiral Amine 3-5
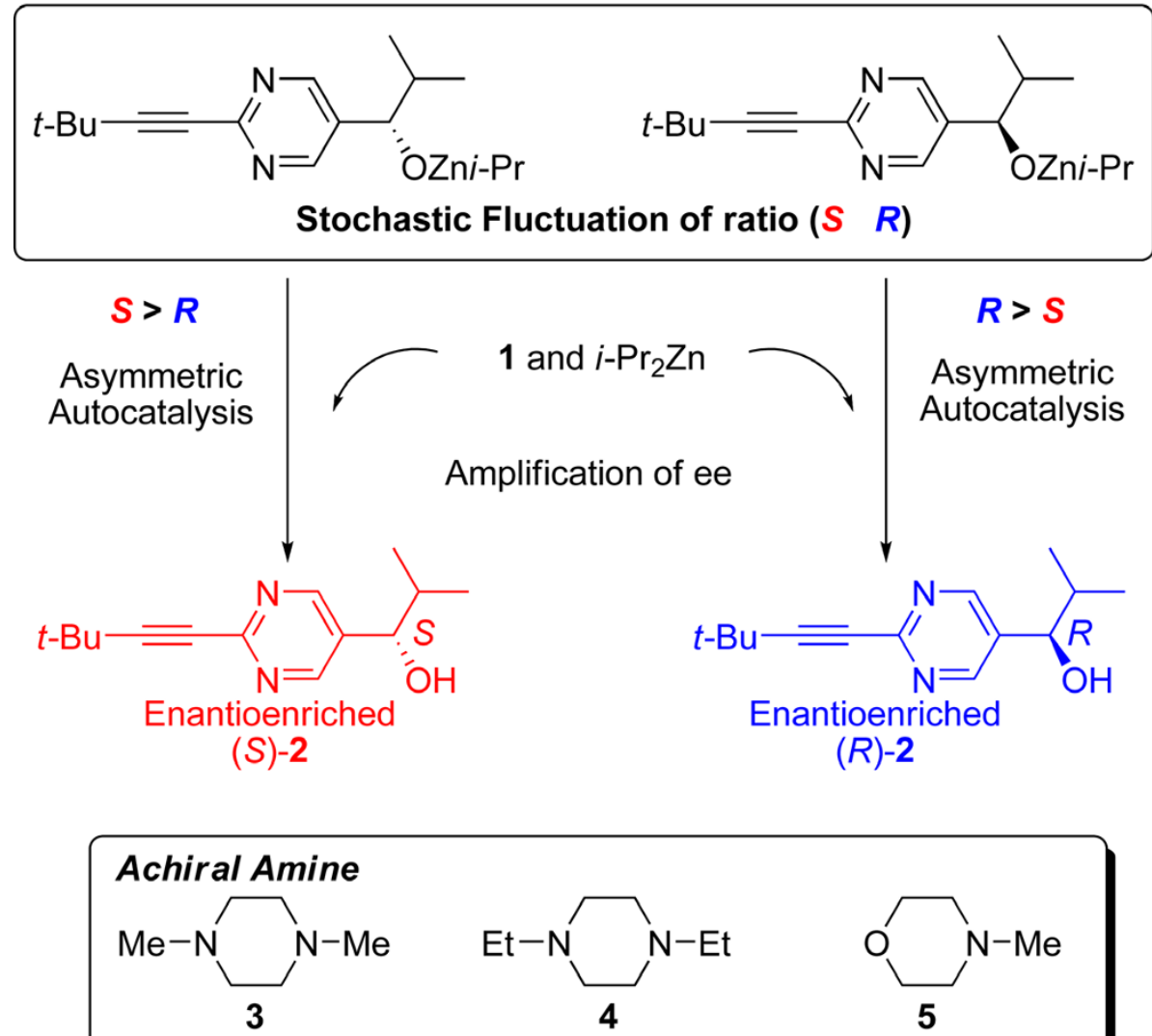

Figure 1 Asymmetric synthesis of pyrimidyl alkanol in the presence of achiral amines without the addition of a chiral substance; After the reaction between pyrimidine-5-carbaldehyde 1 and $i-\operatorname{Pr}_{2} \mathrm{Zn}$ in the presence of achiral amines, asymmetric autocatalysis amplified the spontaneously generated small fluctuation of ee to afford the enantiomerically enriched $(S)$ - or $(R)-5$-pyrimidyl alkanol 2 . 
First, reaction of pyrimidine-5-carbaldehyde 1 with $i-\operatorname{Pr}_{2} \mathrm{Zn}$ in the presence of achiral $N, N^{\prime}$-dimethylpiperazine 3 in toluene, followed by one-pot asymmetric autocatalysis with amplification of ee, was examined. The enantioenriched $(S)$ - or $(R)$-5-pyrimidyl alkanol 2 was obtained. The results are shown in Table 1. To examine the distribution of the absolute configuration of the predominantly formed enantiomer 2, 75 experiments were run under the same reaction conditions. In all cases, enantioenriched 5-pyrimidyl alkanols 2 with either $S$ or $R$ configurations were formed. As shown in Figure 2a, the absolute configurations of the resulting 5-pyrimidyl alkanol 2 exhibited an approximate stochastic distribution (the $S$ form occurred 39 times and the $R$ form occurred 36 times). It should be noted that the ee of the product 2 can be easily amplified significantly by further consecutive asymmetric autocatalytic reactions. That is, by using the alkanol 2 with low to moderate ee obtained in the described method as the asymmetric autocatalyst,

Table 1 Asymmetric synthesis of pyrimidyl alkanol 2 without adding chiral substances by the addition of diisopropylzinc to pyrimidine-5-carbaldehyde 1 in the presence of $\mathbf{N}, N^{\prime}$-dimethylpiperazine 3.

\begin{tabular}{|c|c|c|c|c|c|c|c|c|}
\hline \multirow[t]{2}{*}{ Run } & \multicolumn{2}{|c|}{$\begin{array}{l}\text { Pyrimidyl } \\
\text { alkanol } 2\end{array}$} & \multirow[t]{2}{*}{ Run } & \multicolumn{2}{|c|}{$\begin{array}{l}\text { Pyrimidyl } \\
\text { alkanol } 2\end{array}$} & \multirow[t]{2}{*}{ Run } & \multicolumn{2}{|c|}{$\begin{array}{l}\text { Pyrimidyl } \\
\text { alkanol } 2\end{array}$} \\
\hline & ee & Config. & & ee & Config. & & ee & Config. \\
\hline 1 & 19 & $R$ & 26 & 3 & $R$ & 52 & 36 & $S$ \\
\hline 2 & 18 & $S$ & 27 & 7 & $S$ & 53 & 23 & $S$ \\
\hline 3 & 8 & $R$ & 28 & 4 & $S$ & 54 & 32 & $R$ \\
\hline 4 & 10 & $S$ & 29 & 14 & $R$ & 55 & 32 & $S$ \\
\hline 5 & 11 & $R$ & 30 & 6 & $S$ & 56 & 4 & $S$ \\
\hline 6 & 8 & $S$ & 31 & 6 & $R$ & 57 & 6 & $R$ \\
\hline 7 & 5 & $S$ & 32 & 4 & $S$ & 58 & 12 & $S$ \\
\hline 8 & 9 & $R$ & 33 & 4 & $R$ & 59 & 15 & $S$ \\
\hline 9 & 6 & $S$ & 34 & 3 & $S$ & 60 & 5 & $S$ \\
\hline 10 & 4 & $S$ & 35 & 15 & $S$ & 61 & 42 & $R$ \\
\hline 11 & 4 & $S$ & 36 & 20 & $S$ & 62 & 52 & $R$ \\
\hline 12 & 57 & $R$ & 37 & 18 & $R$ & 63 & 2 & $S$ \\
\hline 13 & 2 & $R$ & 38 & 9 & $R$ & 64 & 43 & $R$ \\
\hline 14 & 37 & $S$ & 39 & 37 & $S$ & 65 & 35 & $R$ \\
\hline 15 & 23 & $R$ & 40 & 27 & $S$ & 66 & 3 & $S$ \\
\hline 16 & 4 & $S$ & 41 & 28 & $R$ & 67 & 2 & $R$ \\
\hline 17 & 6 & $R$ & 42 & 3 & $R$ & 68 & 4 & $S$ \\
\hline 18 & 4 & $S$ & 43 & 9 & $S$ & 69 & 4 & $S$ \\
\hline 19 & 7 & $S$ & 44 & 32 & $S$ & 70 & 42 & $R$ \\
\hline 20 & 47 & $R$ & 45 & 29 & $R$ & 71 & 32 & $R$ \\
\hline 21 & 29 & $R$ & 46 & 11 & $S$ & 72 & 18 & $R$ \\
\hline 22 & 25 & $R$ & 47 & 16 & $R$ & 73 & 6 & $S$ \\
\hline 23 & 10 & $S$ & 48 & 52 & $R$ & 74 & 9 & $R$ \\
\hline 24 & 12 & $S$ & 49 & 9 & $R$ & 75 & 19 & $R$ \\
\hline 25 & 31 & $R$ & 50 & 4 & $S$ & & & \\
\hline 26 & 12 & $S$ & 51 & 19 & $R$ & & & \\
\hline
\end{tabular}

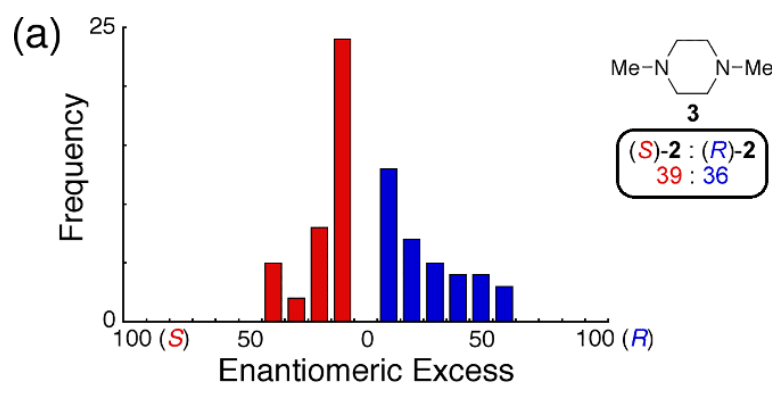

(b)

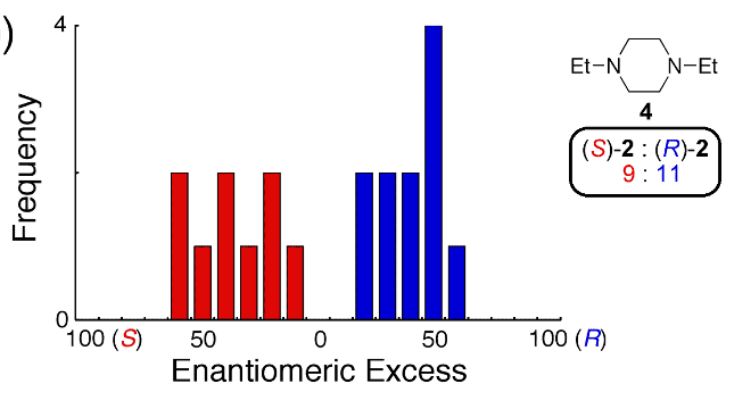

(c)

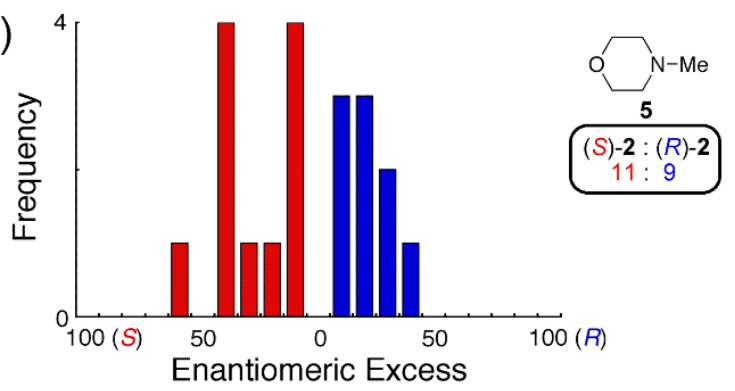

(d)

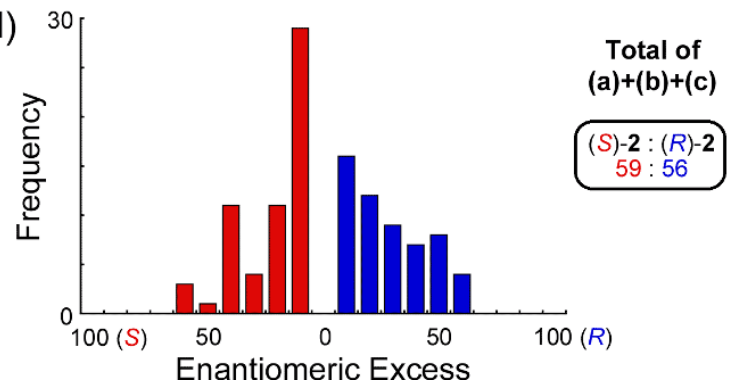

Figure 2 Histogram of the absolute configuration and enantiomeric excess of pyrimidyl alkanol 2. The reaction of aldehyde $\mathbf{1}$ with $i-\mathrm{Pr}_{2} \mathrm{Zn}$ in the presence of (a) $\mathrm{N}_{1} \mathrm{~N}^{\prime}-$

dimethylpiperazine 3, (b) N,N'-diethylpiperazine 4, (c). N-

methylmorpholine 5, (d) total of (a), (b) and (c); stochastic behavior in the formation of (S)- and (R)-5-pyrimidyl alkanols $\mathbf{2}$ was observed in the presence of achiral amines $\mathbf{3 - 5}$, respectively.

additional reactions between pyrimidine-5-carbaldehyde 1 and $i-\operatorname{Pr}_{2} \mathrm{Zn}$ could afford finally almost enantiomerically pure product $\mathbf{2}$ with the same absolute configuration as to the submitted asymmetric autocatalyst, in highly reproducible manner [16]. 
Next, the addition of $i-\mathrm{Pr}_{2} \mathrm{Zn}$ to pyrimidine-5-carbaldehyde 1 in the presence of achiral $N, N^{2}$-diethylpiperazine 4 was examined. The results are summarized in Table 2 and Figure $2 \mathrm{~b}$. The absolute configurations of the pyrimidyl alkanol 2 formed show an approximate stochastic distribution (formation of $S 9$ times and $R 11$ times). The reaction in the presence of achiral $N$ methylmorpholine 5 gave the results of the stochastic formation of $(S)$ - and $(R)$-alkanol 2 (formation of $S 11$ times and $R 9$ times, Table 3 and Figure 2c). The total distribution of alkanol 2 in the presence of achiral amines 3-5 is summarized in Figure 2d. The results of the formation of $(S)-2$ in 59 times and $(R)$ - 2 in 56 times strongly suggest that the reaction is spontaneous absolute asymmetric synthesis.

\section{Experimental}

The typical experimental procedure is as follows: The pyrimidine-5-carbaldehyde 1 ( $37.6 \mathrm{mg}, 0.20 \mathrm{mmol})$ dissolved in $2.0 \mathrm{~mL}$ of toluene was added dropwise over a period of $1 \mathrm{~h}$ to a mixture of $i-\operatorname{Pr}_{2} \mathrm{Zn}(0.40 \mathrm{~mL}$ of $1 \mathrm{M}$ toluene solution, $0.40 \mathrm{mmol}$ ) and achiral $N, N^{\prime}$-dimethylpiperazine $3\left(1.1 \mathrm{mg}, 1.0 \times 10^{-2} \mathrm{mmol}\right)$ in toluene $(4.0$ $\mathrm{mL}$ ) at $0^{\circ} \mathrm{C}$. After the mixture was stirred for a period of $12 \mathrm{~h}$ at $0^{\circ} \mathrm{C}, 6.6 \mathrm{~mL}$ of toluene and $i-\operatorname{Pr}_{2} \mathrm{Zn}(0.80 \mathrm{~mL}$ of 1 $\mathrm{M}$ toluene solution, $0.80 \mathrm{mmol}$ ) were added successively, and the mixture was stirred at $0^{\circ} \mathrm{C}$ for a period of $15 \mathrm{~min}$. The aldehyde 1 ( $75.3 \mathrm{mg}, 0.4 \mathrm{mmol}$ ) in $2.0 \mathrm{~mL}$ of toluene was added dropwise at $0^{\circ} \mathrm{C}$ over a period of $40 \mathrm{~min}$. After the mixture was stirred at $0^{\circ} \mathrm{C}$ for a period of $2 \mathrm{~h}$, the reaction was quenched using $2.4 \mathrm{~mL}$ of $1 \mathrm{M}$ hydrochloric acid. Saturated aqueous sodium hydrogen carbonate (7.2 $\mathrm{mL}$ ) was then added, and the mixture filtered through Celite. The filtrate was extracted using ethyl acetate, dried over anhydrous sodium sulfate, and evaporated. Purification of the residue by silica gel TLC gave the pyrimidyl alkanol 2.

Table 2 Asymmetric synthesis of pyrimidyl alkanol 2 without adding chiral substances by the addition of diisopropylzinc to pyrimidine-5-carbaldehyde 1 in the presence of $N, N^{\prime}$-diethylpiperazine 4

\begin{tabular}{|c|c|c|c|c|c|c|c|c|}
\hline \multirow[t]{2}{*}{ Run } & \multicolumn{2}{|c|}{$\begin{array}{l}\text { Pyrimidyl } \\
\text { alkanol } 2\end{array}$} & \multirow[t]{2}{*}{ Run } & \multicolumn{2}{|c|}{$\begin{array}{l}\text { Pyrimidyl } \\
\text { alkanol } 2\end{array}$} & \multirow[t]{2}{*}{ Run } & \multicolumn{2}{|c|}{$\begin{array}{l}\text { Pyrimidyl } \\
\text { alkanol } 2\end{array}$} \\
\hline & ee & Config. & & ee & Config. & & ee & Config. \\
\hline 1 & 50 & $S$ & 8 & 53 & $S$ & 15 & 36 & $S$ \\
\hline 2 & 57 & $R$ & 9 & 39 & $R$ & 16 & 24 & $S$ \\
\hline 3 & 47 & $R$ & 10 & 40 & $R$ & 17 & 22 & $R$ \\
\hline 4 & 55 & $S$ & 11 & 37 & $S$ & 18 & 5 & $S$ \\
\hline 5 & 14 & $R$ & 12 & 20 & $S$ & 19 & 35 & $R$ \\
\hline 6 & 27 & $R$ & 13 & 47 & $R$ & 20 & 11 & $S$ \\
\hline 7 & 10 & $R$ & 14 & 47 & $R$ & & & \\
\hline
\end{tabular}

Table 3 Asymmetric synthesis of pyrimidyl alkanol 2 without adding chiral substances by the addition of diisopropylzinc to pyrimidine-5-carbaldehyde 1 in the presence of $\mathbf{N}$-methylmorpholine 5

\begin{tabular}{|c|c|c|c|c|c|c|c|c|}
\hline \multirow[t]{2}{*}{ Run } & \multicolumn{2}{|c|}{$\begin{array}{l}\text { Pyrimidyl } \\
\text { alkanol } 2\end{array}$} & \multirow[t]{2}{*}{ Run } & \multicolumn{2}{|c|}{$\begin{array}{l}\text { Pyrimidyl } \\
\text { alkanol } 2\end{array}$} & \multirow[t]{2}{*}{ Run } & \multicolumn{2}{|c|}{$\begin{array}{l}\text { Pyrimidyl } \\
\text { alkanol } 2\end{array}$} \\
\hline & ee & Config. & & ee & Config. & & ee & Config \\
\hline 1 & 34 & $S$ & 8 & 15 & $R$ & 15 & 6 & $S$ \\
\hline 2 & 37 & $R$ & 9 & 33 & $S$ & 16 & 9 & $R$ \\
\hline 3 & 52 & $S$ & 10 & 7 & $R$ & 17 & 29 & $R$ \\
\hline 4 & 33 & $S$ & 11 & 10 & S & 18 & 12 & $S$ \\
\hline 5 & 20 & $R$ & 12 & 6 & $S$ & 19 & 12 & $R$ \\
\hline 6 & 16 & $R$ & 13 & 7 & $R$ & 20 & 27 & $S$ \\
\hline 7 & 33 & $S$ & 14 & 7 & $S$ & & & \\
\hline
\end{tabular}

\section{Conclusions}

We have demonstrated the stochastic formation of $(S)$ and (R)-5-pyrimidyl alkanol 2 from pyrimidine-5-carbaldehyde 1 and $i-\operatorname{Pr}_{2} \mathrm{Zn}$ in the presence of achiral amines without the intervention of a chiral auxiliary. The presence of achiral amines facilitated the initiation of asymmetric autocatalysis by activation of diisopropylzinc. The stochastic behavior of the formation of $(S)$-and $(R)$-5pyrimidyl alkanol 2 was observed in the presence of achiral amines. We believe that the phenomenon reported here constitutes one of the conditions necessary for a spontaneous absolute asymmetric synthesis. In this reaction system involving asymmetric autocatalysis with amplification of ee, the imbalance of enantiomeric purity in the initially forming racemic mixtures that arises from the reaction of achiral reactants becomes overwhelming to afford an enantiomerically enriched product. The mechanism and reaction model for the spontaneous generation of enantiopurity and amplification of ee in asymmetric autocatalysis [22,35-44,52-56] are now under investigation.

\section{Methods}

All reactions were performed under an argon atmosphere. Toluene was distilled under argon in the presence of sodium benzophenone ketyl before use. Toluene solution of diisopropylzinc $(1.0 \mathrm{M})$ is commercially available. Achiral amines 3-5 are commercial sources and were distilled from potassium hydroxide under reduced pressure before use. Pyrimidine-5-carbaldehyde 1 was synthesized and purified according to a reported procedure and was finally purified by sublimation before use. The ee of 5-pyrimidyl alkanol 2 was determined by HPLC using a chiral stationary phase (Daicel Chiralpak IB, eluent 5\% 2-propanol in hexane

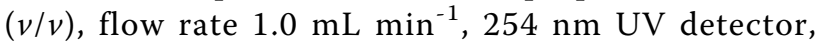
retention time $11.4 \mathrm{~min}$ for $(S)-2,15.9 \mathrm{~min}$ for $(R)$-2). 


\section{Abbreviations}

S: sinister; $R$ : rectus; T: tertiary; l: iso; EE: enantiomeric excess PR: propyl; BU: butyl; M: milli; M: mol/L; G: gram; L: liter; ME: methyl; ET: ethyl; TLC: thin-layer chromatography; HPLC: high performance liquid chromatography; MIN: minute.

\section{Acknowledgements}

This work was supported by a Grant-in-Aid for Scientific Research from Japan Society for the Promotion of Science. The authors thank Ms. Sayaka Kamimura for performing some experiments.

\section{Authors' contributions}

KSo conceived the research project and obtained the research funding. KSu, $\mathrm{KH}$ and DN performed the asymmetric autocatalytic reactions in the presence of achiral amines. TK performed the project and taught how to perform the experiments. KSu, TK and KSo wrote the paper.

\section{Competing interests}

The authors declare that they have no competing interests.

Received: 26 February 2010 Accepted: 18 August 2010 Published: 18 August 2010

\section{References}

1. Mislow K: Absolute asymmetric synthesis: A commentary. Collect Czechoslov Chem Commun 2003, 68:849-863.

2. Bolli M, Micura R, Eschenmoser A: Pyranosyl-RNA: chiroselective selfassembly of base sequences by ligative oligomerization of tetranucleotide-2', $3^{\prime}$-cyclophosphates (with a commentary concerning the origin of biomolecular homochirality). Chem Biol 1997, 4:309-320.

3. Kondepudi DK, Asakura K: Chiral autocatalysis, spontaneous symmetry breaking, and stochastic behavior. Acc Chem Res 2001, 34:946-954

4. Green MM, Park J-W, Sato T, Teramoto A, Lifson S, Selinger RLB, Selinger JV: The macromolecular route to chiral amplification. Angew Chem Int Ed 1999, 38:3139-3154.

5. Girard C, Kagan HB: Nonlinear effects in asymmetric synthesis and stereoselective reactions: ten years of investigation. Angew Chem Int Ed 1998, 37:2922-2959.

6. Zepik H, Shavit E, Tang M, Jensen TR, Kjaer K, Bolbach G, Leiserowitz L, Weissbuch I, Lahav M: Chiral amplification of oligopeptides in twodimensional crystalline self-assemblies on water. Science 2002, 295:1266-1269.

7. Kondepudi DK, Kaufman RJ, Singh N: Chiral symmetry breaking in sodium chlorate crystallization. Science 1990, 250:975-976.

8. Pincock RE, Perkins RR, Ma AS, Wilson KR: Probability distribution of enantiomorphous forms in spontaneous generation of optically active substances. Science 1971, 174:1018-1020.

9. Havinga E: Spontaneous formation of optically active substances. Biochim Biophys Acta 1954, 13:171-174.

10. Viedma C: Chiral symmetry breaking during crystallization: complete chiral purity induced by nonlinear autocatalysis and recycling. Phys Rev Lett 2005, 94:065504.

11. Frank FC: On spontaneous asymmetric synthesis. Biochim Biophys Acta 1953, 11:459-463.

12. Mangel M: Simple theory of relaxation from instabilities. Phys Rev A 1981, 24:3226-3238

13. Iwamoto $\mathrm{K}$ : A reaction model for generation of enantiomers via a stereoselective process by a racemic catalyst. Nippon Kagaku Kaishi 1999, 8:527-531.

14. Soai K, Shibata T, Morioka H, Choji K: Asymmetric autocatalysis and amplification of enantiomeric excess of a chiral molecule. Nature 1995, 378:767-768.

15. Shibata T, Yonekubo S, Soai K: Practically perfect asymmetric autocatalysis using 2-alkynyl-5-pyrimidylalkanol. Angew Chem Int Ed 1999, 38:659-661.

16. Sato I, Urabe $H$, Ishiguro $S$, Shibata $T$, Soai K: Amplification of chirality from extremely low to greater than $99.5 \%$ ee by asymmetric autocatalysis. Angew Chem Int Ed 2003, 42:315-317.

17. Soai K, Shibata T, Sato I: Enantioselective automultiplication of chiral molecules by asymmetric autocatalysis. Acc Chem Res 2000, 33:382-390.

18. Soai K, Shibata T, Sato I: Discovery and development of asymmetric autocatalysis. Bull Chem Soc Jpn 2004, 77:1063-1073.
19. Soai K, Kawasaki T: Discovery of asymmetric autocatalysis with amplification of chirality and its implications in chiral homogeneity of biomolecules. Chirality 2006, 18:469-478.

20. Soai K, Kawasaki T: Asymmetric autocatalysis with amplification of chirality. Top Curr Chem 2008, 284:1-33.

21. Bolm C, Bienewald F, Seger A: Asymmetric autocatalysis with amplification of chirality. Angew Chem Int Ed 1996, 35:1657-1659.

22. Blackmond DG: Asymmetric autocatalysis and its implications for the origin of homochirality. Proc Natl Acad Sci USA 2004, 101:5732-5736.

23. Podlech J, Gehring T: New aspects of Soai's asymmetric autocatalysis. Angew Chem Int Ed 2005, 44:5776-5777.

24. Todd $\mathrm{MH}$ : Asymmetric autocatalysis: product recruitment for the increase in the chiral environment (PRICE). Chem Soc Rev 2002, 31:211-222.

25. Avalos M, Babiano R, Cintas $P$, Jiménez JL, Palacios JC: Chiral autocatalysis: where stereochemistry meets the origin of life. Chem Commun 2000, 11:887-892.

26. Shibata T, Yamamoto J, Matsumoto N, Yonekubo S, Osanai S, Soai K: Amplification of a slight enantiomeric imbalance in molecules based on asymmetric autocatalysis. The first correlation between high enantiomeric enrichment in a chiral molecule and circularly polarized light. J Am Chem Soc 1998, 120:12157-12158.

27. Lutz F, Igarashi T, Kinoshita T, Asahina M, Tsukiyama K, Kawasaki T, Soai K: Mechanistic insights in the reversal of enantioselectivity of chiral catalysts by achiral catalysts in asymmetric autocatalysis. J Am Chem Soc 2008, 130:2956-2958.

28. Kawasaki T, Matsumura $Y$, Tsutsumi T, Suzuki K, Ito M, Soai K: Asymmetric autocatalysis triggered by carbon isotope $\left({ }^{13} C /{ }^{12} C\right)$ chirality. Science 2009, 324:492-495.

29. Kawasaki T, Shimizu M, Nishiyama D, Ito M, Ozawa H, Soai K: Asymmetric autocatalysis induced by meteoritic amino acids with hydrogen isotope chirality. Chem Commun 2009, 29:4396-4398.

30. Soai K, Osanai S, Kadowaki K, Yonekubo S, Shibata T, Sato I: $d$ - and IQuartz-promoted highly enantioselective synthesis of a chiral compound. J Am Chem Soc 1999, 121:11235-11236.

31. Kawasaki T, Jo K, Igarashi H, Sato I, Nagano M, Koshima H, Soai K: Asymmetric amplification using chiral cocrystals formed from achiral organic molecules by asymmetric autocatalysis. Angew Chem Int Ed 2005, 44:2774-2777.

32. Kawasaki T, Suzuki K, Hakoda Y, Soai K: Achiral nucleobase cytosine acts as an origin of homochirality of biomolecules in conjunction with asymmetric autocatalysis. Angew Chem Int Ed 2008, 47:496-499.

33. Kawasaki T, Sato M, Ishiguro I, Saito T, Morishita M, Sato I, Nishino H, Inoue $Y$, Soai $K$ : Enantioselective synthesis of near enantiopure compound by asymmetric autocatalysis triggered by asymmetric photolysis with circularly polarized light. J Am Chem Soc 2005, 127:3274-3275

34. Mills WH: Some aspects of stereochemistry. Chem and Ind 1932, 51:750-759.

35. Pályi G, Micskei K, Zékány L, Zucchi C, Caglioti L: Racemates and the Soai reaction. Magy Kem Lapja 2005, 60:17-24.

36. Islas JR, Lavabre D, Grevy J-M, Lamoneda RH, Cabrera HR, Micheau J-C, Buhse T: Mirror-symmetry breaking in the Soai reaction: A kinetic understanding. Proc Natl Acad Sci USA 2005, 102:13743-13748.

37. Lavabre D, Micheau JC, Islas JR, Buhse T: Kinetic insight into specific features of the autocatalytic Soai reaction. Top Curr Chem 2008, 284:67-96

38. Gridnev ID, Serafimov JM, Quiney H, Brown JM: Reflections on spontaneous asymmetric synthesis by amplifying autocatalysis. Org Biomol Chem 2003, 1:3811-3819.

39. Saito $Y$, Hyuga $H$ : Rate equation approaches to amplification of enantiomeric excess and chiral symmetry breaking. Top Curr Chem 2008, 284:97-118.

40. Lente G: Stochastic kinetic models of chiral autocatalysis: A general tool for the quantitative interpretation of total asymmetric synthesis. J Phys Chem A 2005, 109:11058-11063.

41. Shao J, Liu L: Stochastic fluctuations and chiral symmetry breaking: exact solution of Lente model. J Phys Chem A 2007, 111:9570-9572.

42. Micskei K, Rabai G, Gal E, Caglioti L, Pályi G: Oscillatory symmetry breaking in the Soai reaction. J Phys Chem B 2008, 112:9196-9200. 
43. Crusats J, Hochberg D, Moyano A, Ribó JM: Frank model and spontaneous emergence of chirality in closed systems. Chem Phys Chem 2009, 10:2123-2131.

44. Barabas B, Caglioti L, Micskei K, Pályi G: Data-based stochastic approach to absolute asymmetric synthesis by autocatalysis. Bull Chem Soc Jpn 2009, 82:1372-1376.

45. Soai K, Shibata T, Kowata Y: Preparation of optically active pyrimidylalkyl alcohols by spontaneous absolute asymmetric synthesis. Jpn Kokai Tokkyo Koho 1997. JP 09025269 A 19970128.

46. Soai K, Sato I, Shibata T, Komiya S, Hayashi M, Matsueda Y, Imamura H, Hayase T, Morioka H, Tabira H, Yamamoto J, Kowata Y: Asymmetric synthesis of pyrimidyl alkanol without adding chiral substances by the addition of diisopropylzinc to pyrimidine-5-carbaldehyde in conjunction with asymmetric autocatalysis. Tetrahedron: Asymmetry 2003, 14:185-188.

47. Kawasaki T, Suzuki K, Shimizu M, Ishikawa K, Soai K: Spontaneous absolute asymmetric synthesis in the presence of achiral silica gel in conjunction with asymmetric autocatalysis. Chirality 2006, 18:479-482.

48. Singleton DA, Vo LK: A few molecules can control the enantiomeric outcome. Evidence supporting absolute asymmetric synthesis using the Soai asymmetric autocatalysis. Org Lett 2003, 5:4337-4339.

49. Soai K, Watanabe M, Koyano M: Synthesis of hydroxy ketones by chemoselective alkylation of keto aldehydes with dialkylzincs catalyzed by amino alcohol, diamine, or dilithium salt of piperazine. Bull Chem Soc Jpn 1989, 62:2124-2125.

50. Niwa S, Soai K: Asymmetric synthesis using chiral piperazines. Part 3. Enantioselective addition of dialkylzincs to aryl aldehydes catalysed by chiral piperazines. J Chem Soc Perkin Trans 1 1991, 2717-2720.

51. Lennartson A, Hedström A, Håkansson M: Diisopropyl $\left(N, N, N^{\prime}, N^{\prime}-\right.$ tetramethylethylenediamine)zinc(II), the first crystal structure of a diisopropylzinc complex. Acta Cryst 2007, E63:m123-m125.

52. Sato I, Omiya D, Igarashi H, Kato K, Ogi Y, Tsukiyama K, Soai K: Relationship between the time, yield, and enantiomeric excess of asymmetric autocatalysis of chiral 2-alkynyl-5-pyrimidyl alkanol with amplification of enantiomeric excess. Tetrahedron: Asymmetry 2003, 14:975-979.

53. Blackmond DG, McMillan CR, Ramdeehul S, Schorm A, Brown JM: Origins of asymmetric amplification in autocatalytic alkylzinc additions. J Am Chem Soc 2001, 123:10103-10104.

54. Gridnev ID, Serafimov JM, Brown JM: Solution structure and reagent binding of the zinc alkoxide catalyst in the Soai asymmetric autocatalytic reaction. Angew Chem Int Ed 2004, 43:4884-4887.

55. Klankermayer J, Gridnev ID, Brown JM: Role of the isopropyl group in asymmetric autocatalytic zinc alkylations. Chem Commun 2007, 3151-3153.

56. Schiaffino L, Ercolani G: Unraveling the mechanism of the Soai asymmetric autocatalytic reaction by first-principles calculations: induction and amplification of chirality by self-assembly of hexamolecular complexes. Angew Chem Int Ed 2008, 47:6832-6835.

doi:10.1186/1759-2208-1-5

Cite this article as: Suzuki et al: Spontaneous absolute asymmetric synthesis promoted by achiral amines in conjunction with asymmetric autocatalysis. Journal of Systems Chemistry 2010 1:5.

Publish with ChemistryCentral and every
scientist can read your work free of charge
"Open access provides opportunities to our
colleagues in other parts of the globe, by allowing
anyone to view the content free of charge."
W. Jeffery Hurst, The Hershey Company.
- available free of charge to the entire scientific community
- peer reviewed and published immediately upon acceptance
- cited in PubMed and archived on PubMed Central
- yours - you keep the copyright
Submit your manuscript here:
http:/lwww.chemistrycentral.com/manuscriptt

